\title{
Indoor particulate matter measurement as a tool in the process of the implementation of Smoke-free Hospitals
}

\author{
S. Nardini1, R. Cagnin1, G. Invernizzi2,3, A. Ruprecht2, \\ R. Boffi 2 , S. Formentini ${ }^{1}$
}

ABSTRACT: Indoor particulate matter measurement as a tool in the process of the implementation of Smoke-free Hospitals. S. Nardini, R. Cagnin, G. Invernizzi, A. Ruprecht, R. Boffi, S. Formentini.

Aim of the study: There are International and National standards that requires hospitals and health premises to be smoke-free. According to recent data from Italy and other European Countries, smoking is a widespread habit in hospitals. To get smoke-free hospitals in an Italian region, we have adopted the European Code for smoke-free hospitals, which sets standards and provides instruments for its implementation. According to the Code, whenever possible, each step towards a smoke-free hospital, should be shared by all staff. As a mean for achieving this goal, in our region the certification of single units as smoke-free units has been chosen. For getting the certification, besides implementing the Code, we planned to use ETS (Environmental Tobacco Smoke) monitoring, as ETS should not be present in hospitals. As a marker of ETS we have chosen Particulate Matter (PM), as it can easily be measured in real-time with a portable instrument and, when other even outdoor - sources of combustion can be ruled out, it is an accurate detector of cigarette smoke. Here the first experience of measuring $\mathbf{P M}$ in hospitals for monitoring ETS and certificating smoke-free health premises, is described.

Materials and methods: PM measurements were carried out without any previous notification in different areas of two Network hospitals of the Veneto Region, during a single working day. A real time laser-operated aerosol mass analyser was used. Several classes of PM (PM1, PM2.5, PM7, PM10, TSP Total Suspended Particles) were measured.

Results: Outdoor PM levels were found to be repeatedly lower than the annual official limits of $65 \mathrm{mcg} / \mathrm{m} 3$ and around the 24 hour official limits of $15 \mathrm{mcg} / \mathrm{m} 3$ [15 to 20 $\mathrm{mcg} / \mathrm{m} 3$, with an overall mean $( \pm$ SD) of 17.8 (1.9)] throughout the whole day. Very good indoor air quality was found in the operating theaters and isolation department, where PM2.5 concentrations were much lower than outdoor levels $[1.6(0.9)$ and $5.9(0.6) \mathrm{mcg} / \mathrm{m} 3$, respectively]. No increase in PM pollution was found in the surveyed medical offices, halls and waiting rooms where smoking was positively forbidden [PM2.5 concentrations of $\mathbf{1 4 . 8}$ (2.2) and $12.9(1.1) \mathrm{mcg} / \mathrm{m} 3$ ] except in a medical office and in two coffee rooms for staff only where high PM levels were recorded [PM2.5 58.7 (29.1), 27.0 (10.6) and 107.1 (47.8) $\mathrm{mcg} / \mathrm{m} 3$ ] and an offence of smoking restrictions could be proved.

Conclusions: The measurement of PM in hospital for monitoring ETS proved to be both feasible and sensible. PM measurements with a portable instrument can be used both for controlling the compliance with rules or chosen standards and for educating staff about smoking related hazards, thus gaining consensus for the implementation of the tobacco control policy. In our experience, PM measurement can be used as an aid inside all actions designed by the European Code for smoke-free hospitals.

Monaldi Arch Chest Dis 2004; 61: 3, 183-192.

Keywords: Tobacco smoking, Environmental tobacco smoke, Health staff, Smoke-free hospitals, Particulate Matter.

1 Pulmonary and TB Unit, Vittorio Veneto General Hospital, Italy; Veneto Region - 2004-2006 Regional Plan for the prevention of smoking related diseases.

2 Tobacco Control Unit, National Cancer Institute, Milan.

3 SIMG, Italian College of GPs, Milan.

Correspondence: Stefano Nardini, Pulmonary and TB Unit, Vittorio Veneto General Hospital, Viale Forlanini, 71 - 31029 Vittorio Veneto (TV) Italy; e-mail: snardini@qubisoft.it.

This study has been partly financed with an unrestricted educational grant from AIMAR (Italian Scientific Society for the Study of Respiratory Disease).

\section{Introduction}

Since 1993, the World Health Organisation (WHO) defined health services as the central point in actions aimed at getting a smoke-free community [1] and according to the Ottawa conference, hospitals should not only treat diseases but also promote health [2].Tobacco smoking - both active and passive - can be considered the most important cause of preventable death in developed Countries.

But health promotion is not the only reason why hospitals should be smoke-free. As any other workplace, hospitals should be smoke-free also for preserving the health of its workers, be he/she a non-smoker or smoker, by protecting the former 
from Environmental Tobacco Smoke (ETS) and by helping the latter for smoking cessation [3-4]. This does not seem to be the case at least in some countries in Europe where smoking prevalence of health staff has been surveyed: indeed, in many Countries in the World smoking amongst health staff is a common enough habit $[5,6,7]$ and smokers smoke inside hospitals, even if forbidden [5].

To address this important point (indeed a crucial point in the fight against tobacco related diseases) in the last four years, two projects financed by the European Community have designed a complete programme to achieve smoke free hospitals and a European Network (European Network of Smoke-free Hospitals= ENSH) $($ Annex 1) has been launched. A "code" has been produced (the European Code for Smoke- free Hospitals) to be used as a guideline and as a reference both for selfaudit and for external audit (table 1).

According to the ENSH Self audit questionnaire, hospitals should comply with a certain number of conditions required by the Network. Every item in the questionnaire, enters a score system that marks the steps toward a smoke- free environment, the full score defining a hospital as a Smokefree Hospital.

The code has recently started to be implemented in an Italian region (Veneto) where the smoking

Table 1. - The european code for smoke-free hospitals

\section{Commitment}

1. Engage decision-makers. Inform all personnel and patients.

\section{Communication}

2. Appoint a working group. Develop a strategy and implementation plan.

\section{Education \& Prevention}

3. Set up a training plan to instruct all staff on how best to approach smokers.

\section{Identification \& Cessation Support}

4. Organise cessation support facilities for patients and staff in the organisation and ensure continuity of support on discharge into the community.

\section{Tobacco Control}

5. Indicate smoking zones clearly, as long as they are considered necessary, keeping them away from clinical and reception areas.

\section{Environment}

6. Adopt appropriate signage, including posters, signposts, etc. and remove all incentives to smoke (such as ashtrays, tobacco sales, etc.).

Healthy Workplace

7. Support systems are in place to protect and promote the health of all that work in the hospital.

Review \& Compliance

8. Renew and broaden information to maintain commitment to the policy.

\section{Monitoring}

9. Ensure follow-up and quality assurance.

\section{Policy implementation}

10. First convince, then constrain considering legislation if needed. Have patience! control is historically a little ahead than the National mean, as a part of a comprehensive programme of tobacco control.

In the first phase, the current situation of smoking control in hospitals and health districts has been audited, by means of the ENSH self-audit questionnaire: The second phase, in the progressive path designed by ENSH with three levels of adherence to the Code (table 2) - is to improve all the actions for tobacco control, involving all staff.

In Veneto, a region situated in the north east of Italy, with 4.5 million inhabitants, a working group (see Annex 1) is carrying out the implementation process of the European code by recognising, in each hospital, single units or wards, as "smokefree" units and officially certifying them (in a publicly visible way).

This certification process will consist of two steps: 1 . a self-audit; 2 . an external audit, aimed at measuring the exposition (if any) due to environmental tobacco. If levels of exposition not higher than outdoor air are detected, ETS can be ruled out and the certification given.

PM measurements were chosen as a marker of ETS, because worries about PM indoor pollution due to ETS are increasingly appreciated by lay people [8] and because recent technological advances have allowed the monitoring of PM values in real time with the aid of portable and userfriendly instruments [9].

As a preliminary experience, we wanted to verify the feasibility of the technique, and its introduction as a criterion for certifying a health premise as smoke- free.

In each hospital we surveyed all areas, with special attention to the areas which in a

previous survey on Italian Hospitals [10] were reported to be plagued by ETS: i.e. Kitchens $(84.6 \%)$, Toilets $(83.3 \%)$ and Waiting rooms $(70.9 \%)$.

This paper reports the results of our first experience, carried out in two hospitals which joined the network, which confirms the feasibility of such a control and its possible use for certification.

To the best of our knowledge this is the first time that PM has been measured in hospitals with the aim of detecting ETS, so getting the elements for certification of a smoke-free health environment.

Table 2. - Level of partecipation to the ensh

Participation and registration with the European Network will be on three levels:

Bronze

Denotes commitment and endorsement of Codes $1 \& 2$.

Silver

Denotes achievement of the European Minimum Standard Policy.

Gold

Denote certified attainment of a Smoke-Free environment. 


\section{Methods}

PM measurements were carried out without a previous notice in halls, clinics, operating theaters, medical offices, waiting rooms, kitchens, toilets and coffee rooms in departments of two Network hospitals of the Veneto Region, during a working day. A laser-operated aerosol mass analyser was used (Aerocet, Metone Instruments, Grant Pass, Oregon, US). The instrument calculates the concentration of several classes of PM (PM1, PM2.5, PM7, PM10, TSP) by analysing air samples every 2 minutes. PM2.5 was chosen as representative of ETS pollution (see Discussion). by analysing air samples every 2 minutes. The instrument is precalibrated and validated by comparison with gravimetric EPA FRM (Federal Reference Method) and the equivalent according to Italian Standard (see appendix). The analyser is pocket-sized, operates automatically with a battery autonomy for up to 8 hours; data are stored on the internal memory, can be visualized immediately on display and subsequently downloaded on a computer. All the data were collected on the same day, taking a time-table record of the different places with the instrument continuously working. The overall time of measurement was 10 hours. Technical details are described in the Appendix.

\section{Results}

Particulate matter concentration recorded in the different places of one hospital are shown in table 3.

Throughout the whole day outdoor PM2,5 levels were found repeatedly lower than the average annual official limits of $65 \mathrm{mcg} / \mathrm{m} 3$ and around the 24 hour average limits of $15 \mathrm{mcg} / \mathrm{m} 3$, according to the US EPA, with recording ranging between 15 and $20 \mathrm{mcg} / \mathrm{m} 3$, and an overall mean $( \pm \mathrm{SD})$ of $17.8(1.9) \mathrm{mcg} / \mathrm{m} 3$. Very good indoor air quality was found in the hospitals in areas where smoking policy was strictly complied with, and particularly in operating rooms and isolation departments, where mean PM2.5 concentrations were much lower than outdoor levels [(1.6 (0.9) and 5.9 (0.6) $\mathrm{mcg} / \mathrm{m} 3$, respectively], revealing the efficiency of special air depuration systems installed to reduce viral and bacterial pollution.

In addition, no increase in PM pollution was found in medical offices, halls and waiting rooms where smoking was positively forbidden, with PM2.5 concentrations of 14.8 (2.2) and 12.9 (1.1) $\mathrm{mcg} / \mathrm{m} 3 \mathrm{~m} 3$, respectively. In these areas PM values were similar to outdoor recordings, an expected result in confined ambient without additional

Table 3. - Peak PM2.5 concentrations in different places monitored in two hospitals

\begin{tabular}{lccc}
\hline Place & Smoking ban observed/respected & PM2.5 indoor* & PM2.5 outdoor \\
\hline operating room & yes & $1.6(0.9)$ & $18.3(1.2)$ \\
isolation department & yes & $5.9(0.6)$ & $15.4(1.8)$ \\
waiting room & yes & $12.9(1.1)$ & $20.0(1.9)$ \\
medical office 1 & yes & $14.8(2.2)$ & $15.4(1.8)$ \\
medical office 2 & no & $58.7(29.1)$ & $17.5(3.3)$ \\
coffee room 1 & no & $27.0(10.6)$ & $17.5(3.3)$ \\
coffee room 2 & no & $107.1(47.8)$ & $18.3(1.2)$ \\
\hline
\end{tabular}

*mcg/m³ (SD), 30 minutes average minimum.

Overall Indoor \& Average outdoor PM2,5 concentrations

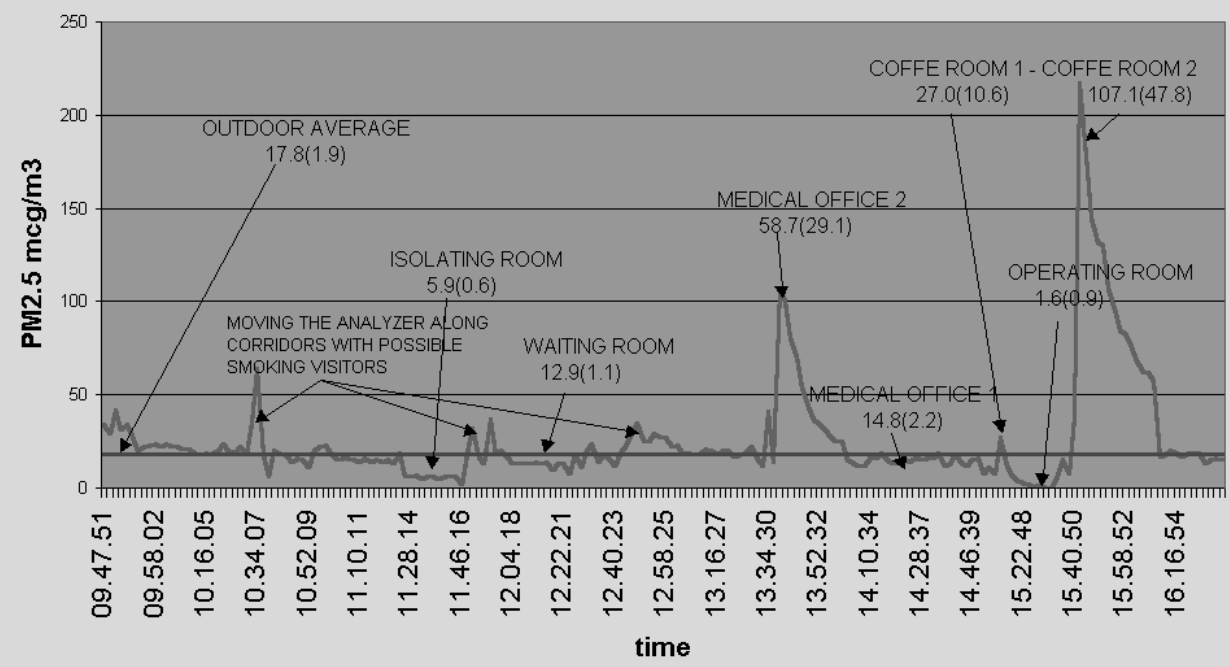

Fig. 1. - Overall $\mathrm{PM}_{2.5}$ during a 10 hour continuous monitoring in different places of one hospital. 
combustion sources, due to the rapid distribution of atmospheric PM inside buildings. In the few places where smoking restrictions were disregarded, PM levels were promptly individuated, as shown by high pollution in a medical office and in two coffee rooms [PM2.5 58.7 (29.1), 27.0 (10.6) and 107.1 (47.8) $\mathrm{mcg} / \mathrm{m} 3$, respectively. Some sharp peaks were detected along the corridors during the analyser transfer from one room to another probably due to smoking visitors although no smokers have been noticed. The graphic representation of the overall continuous recordings is shown in figure 1: the different places are shown at the different times on the lines for PM2.5, with the mean PM2.5 outdoor concentration indicated as a reference.

\section{Discussion}

As emphasised in the introduction, due to their recognized role as centres for promoting health, hospitals have the privilege of positively influencing tobacco control. However, recent surveys about smoking habits in leading hospitals in Italy revealed a high percentage of smokers among hospital staff, along with a high prevalence of exposure to passive smoking. In a previous study carried out in Italy [10], health staff did not significantly differ from the general population with respect to smoking attitudes and the knowledge of smoking related issues. Moreover, the same study showed that in female gender, the prevalence of smokers among health staff is higher than among the general population when matched for age group and educational level while, among males, the prevalence is roughly the same [10].
In their study Zanetti and co-workers [11] observed a rate of personnel reporting exposure to passive smoking of $88 \%$ inside the hospital especially in cooking areas, at information desks and in corridors despite existing smoking bans in place. Another survey conducted among hospital pulmonary physicians conducted by one of us, revealed [12] also the need for information about indoor pollution by tobacco smoking. In conclusion, even if in Italy there have been laws forbidding smoking inside health premises since 1975, smoking can be considered a widespread habit. Some $33.3 \%$ of all staff are smokers (males $30.8 \%$ and females $34.9 \%$ ) with a mean number of cigarettes smoked per day of 13.9 (S.D. 8.9) [12]. According to health staff, smokers smoke while on duty: some $80 \%$ of low nicotine dependent smokers and more than $90 \%$ of highly dependent smokers report smoking inside hospitals [10].

Hospitals and health districts have a leading role and responsibility not only in spreading educational messages on tobacco but also in showing a tight compliance with them [13]. The educational value of smoking policy measures is emphasised by its implementation in health agencies. Such a critical role is emphasized by the daily massive number of in-hospital contacts with citizens of all ages and different social status. However, for the reasons already recorded, the compliance with $\mathrm{Na}-$ tional and International standards of smoking control in hospitals is very difficult and, so far, nearly impossible. It is a problem not only in Italy. Recent surveys have also demonstrated a high prevalence of smokers in hospital staff throughout Europe [14]. In summary, while smoke- free hospitals (and smoke-free health premises) are absolutely neces-

Table 4. - Results of the first Ensh self-audit questionnaire in the Veneto Region (Note: The characters of each health district are hidden under a PIN, known only to the central level and to the self-surveyed District. The red lines show the two SD).

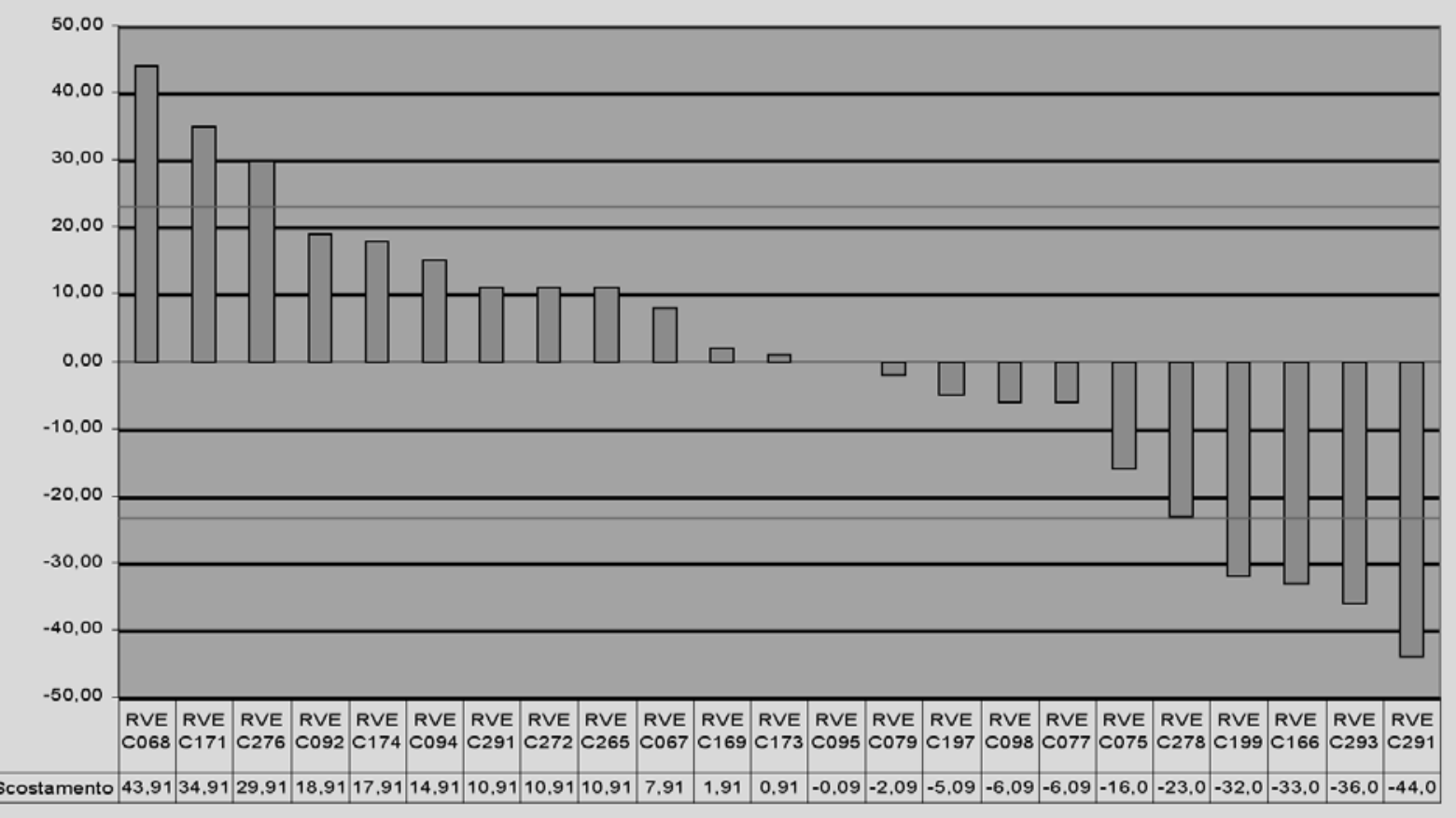


sary (because they are workplaces as well as places where health is promoted), the process of implementation is very difficult and far from achieving its goal. The European Code for smokefree hospitals has been designed to help the implementation process

In Italy, where actions have already been carried out to attain smoke- free hospitals [15] in the year 2002, the European Code started to be implemented in the Veneto region as a part of a comprehensive programme of tobacco control designed according to the Surgeon General Standards [16].

The first step consisted of an audit on the current situation of smoking control in hospitals and health districts using the ENSH self-audit questionnaire. The results of this first survey (table 4) showed a patchy pattern with different situations in different health districts, and overall demonstrated that health premises are not smoke-free.

The second step, along the ENSH implementation model, was to involve staff in tobacco control in a progressive way. So the Veneto group decided to firstly acknowledge single units or wards, as "smoke- free" units, by officially certifying them in each hospital. This certification process should include a "visit" made by external staff (provided by the Regional working group) without previous notice, aimed at measuring the exposition due to environmental tobacco smoke. If this visit detects levels of exposition under the threshold established by the existing laws, ETS is assumed to be absent and the certification given for a set period of time.

A smoke- free environment (i.e. an environment where no ETS can be detected) can be evaluated by measures of individual exposure like urine or saliva cotinine levels in non smokers [17], or by environmental measures of tobacco smoke pollutants like nicotine [18], carbon monoxide [19] or PM [18, 19].

A number of pros and cons characterise each of these different measures in terms of specificity, sensitivity, readiness of response, potential influence on the general public (awareness of hazards which can explain higher or lower levels of effectiveness), and time and resource costs (table 5).

In this grading, cotinine is expensive, indirect, low-impressive but quite specific and sensitive; nicotine is very specific and sensitive, but expensive, low-impressive and indirect; carbon monox-

Table 5. - Comparison among diffent indicators of environmental tobacco smoke.

\begin{tabular}{|l|l|l|l|l|l|}
\hline $\begin{array}{l}\text { Type of } \\
\text { assessement }\end{array}$ & Specific & Sensitive & Quick & Impressive & Costly \\
\hline $\begin{array}{l}\text { Ambient } \\
\text { nicotine }\end{array}$ & +++ & +++ & $+/--$ & $+/--$ & +++ \\
\hline $\begin{array}{l}\text { Saliva, urine } \\
\text { cotinine }\end{array}$ & $++/-$ & $++/-$ & $+/--$ & $+/--$ & +++ \\
$\begin{array}{l}\text { Ambient } \\
\text { carbon }\end{array}$ & $+/--$ & $+/--$ & +++ & +++ & $+/--$ \\
\hline $\begin{array}{l}\text { Ambient } \\
\text { particulate } \\
\text { matter }\end{array}$ & $+/--$ & +++ & +++ & +++ & $+/--$ \\
\hline
\end{tabular}

ide has both low specificity and sensitivity, but is direct, impressive and quite cheap; finally, PM measurement is considered of low specificity but endowed with high sensitivity, direct, impressive and quite inexpensive.

We decided to utilise PM measurements as the objective parameter of clean air for accreditation of Smoke - free Units in the Smoke - free Hospital Network, because basic information exists on PM as a dangerous pollutant and worries about PM indoor pollution are widely appreciated by lay people. Moreover, indoor levels can be compared to well known outdoor limits, and recent technological advances allow for the monitoring of PM values in real time with the aid of portable and friendly-user instruments. PM2.5 was chosen as tobacco smoke indicator because the PM part of the tobacco smoke is composed mostly by particles sized less than $2.5 \mu \mathrm{m}$ in diameter.

In addition, since PM2.5 particles have a very long deposition time, and distribute rapidly into the whole ambient because of the influence of air turbulence, are therefore more representative of the real indoor ETS pollution.

Finally, PM measurements imply neither an active collaboration by the staff involved in the survey nor the asking for personal organic samples, which can be annoying.

As for the PM measurements we carried out, our experience showed very good air quality in the surveyed areas of both hospitals. As expected, isolation departments and the operating theaters showed the lowest concentration of PM, while a fairly good indoor air quality was found in medical offices and waiting rooms where smoking bans were respected, with PM levels lower than outdoors'. In one hospital, where the survey was more detailed, three areas were detected where ETS was present, produced by active smoking inside Hospital, notwithstanding existing smoking ban. One of these places was indeed a medical office that showed PM.

Concentrations of about a 3 fold 24 hour average limits were found inside a medical office where smoking ban was not observed, while the highest pollution was found in coffee room 2, with PM2.5 reaching concentrations 5 fold 24 hour average outdoor limits. So, PM measurements led to an objective measure of ETS and to a patent demonstration of failed compliance with existing rules.

In the context of the implementation process towards smoke-free hospitals, according to the standards set by the European Code of Smokefree Hospital, these findings will be used both for providing evidence of violations and for educating staff to health and increasing their commitment to a smoke- free hospital. Which one of these possible uses will be more emphasised, will depend on the local situation.

Our preliminary observations suggest that PM measurement can be a practical, reproducible and economical tool to the aim of a smoke- free hospital. In fact many hospital facilities can be monitored in a few hours, and if necessary, the results can be discussed on the spot with hospital staff and officers to disseminate the commitment to air qual- 
ity control as a way to implement tobacco control.

Atmospheric PM pollution is a good reference. For the process of accreditation we are planning an operational protocol requiring a number of PM measurements in standard facilities (medical offices, operating rooms, waiting rooms, cooking areas, information desks) with a resulting minimum score, which will be added to the score of the self audit questionnaires.

In conclusion, on the basis of our first experiences, we think that a model combining either the auditing process according to the ENSH code or repeated objective samples of ETS through PM as a measure of the compliance with the standards of ENSH can be the key to achieve smoke-free hospitals.

\section{References}

1. World Health Organisation. No tobacco day, 1993. Tobacco Alert, May, 1993.

2. World Health Organisation. The Ottawa Charter for health promotion. Italian Translation in: Salute e territorio, 1989 (64/65): 14-17.

3. World Health Organisation (Europe). Tobacco free initiative. Why smoking in the workplace matters: an employer's guide. WHO - Europe Copenhagen, 2002.

4. U.S Dept. Of Health and Human Services. Centers for disease control and prevention. Office on Smoking and health. Wellness Council of American / American Cancer Society. Making your workplace smoke-free: a decision maker's guide. U.S Dept. Of health and Human Services. Centers for disease control and prevention. Office on Smoking and health, 2000.

5. Nardini S, Bertoletti R, Rastelli V, Ravelli L, Donner CF. Personal smoking habit and attitude toward smoking among the health staff of a general hospital. Monaldi Arch Chest Dis 1998; 53: 74-78.

6. Li HZ, Rosenblod L. Chinese physicians' cigarette smoking habits and their anti-smoking counselling practice. Health Promotion International 1996; 11: 89-94.

7. Willaing, I, Ladelund, S. Smoking behaviour among hospital staff still influences counselling on smoking. Nicotine and Tobacco Research.

8. Repace JL, Lowrey AH. Indoor air pollution, tobacco smoke and public health. Science 1980; 208: 464-69.

9. Invernizzi G, Ruprecht A, Mazza R, Paredi P, Boffi R. Real-time measurement of indoor particulate matter originating from environmental tobacco smoke: a pilot study. Epidemiol Prev 2002; 26: 30-34.

10. Nardini S, Carrozzi L, Bertoletti R, Matteelli G, Sabato E, Del Donno M. The AIPO target project "No smoking hospitals": descriptive results of the first epidemiological phase. Rass Patol App Resp 2001; 16: 261-272.

11. Zanetti F, Gambi A, Bergamaschi A, Gentilini F, De Luca G, Monti C, Stampi S. Smoking habits, exposure to passive smoking and attitudes to a non-smoking policy among hospital staff. Public Health 1998; 112: 57-62.

12. Nardini S, Bertoletti R, Rastelli V, Donner CF. The influence of personal tobacco smoking on the clinical practice of Italian chest physicians. Eur Respir J 1998; 12: $1450-3$.

13. Tillgren P, Jansson M, Höijer Y, Ullén H. Maintaining a smoke-free policy: an observational and interview study at a university hospital in Sweden. Eur J Cancer Prev 1998 Oct; 7 (5): 403-8.

14. Dautzenberg, B. A survey of smoking prevalence among heatlh staff in Europe. Helsinki, World Conference on Tobacco or health.

15. Nardini S, Carrozzi L, Bertoletti R, Donner CF. The AIPO target project for smoke-free hospitals - 1997. Rass Patol App Resp 1998; 13: 201-205.

16. U.S. Public health Service - Dept of Health and Human Services. Reducing tobacco use- A report of the Surgeon General - Executive Summary. Atlanta (GEO) 2000.

17. Benowitz N. Cotinine as a biomarker of environmental tobacco smoke exposure. Epidemiologic Reviews 1996; 18: 188-204.

18. Wakefield MA, Chaloupka FJ, Kaufman NJ, Orleans CT, Barker DC, Ruel EE. Effect of restrictions on smoking at home, at school, and in public places on teenage smoking: cross sectional study. BMJ 2000; 321: 333-7.

19. Klepeis NE, Ott WR, Repace JL. The effect of cigar smoking on indoor levels of carbon monoxide and particles. J Expo Anal Environ Epidemiol 1999; 9: 622.

\section{APPENDIX}

\section{ANALYSER AND CALIBRATION METHODS DESCRIPTION}

\section{ANALYSER DESCRIPTION}

The Aerosol Mass Particulate Monitor Model AEROCET 531, produced by Metone Instruments Inc. of Grants Pass (Oregon, USA), a hand held analyser, provides a low cost and real time way to monitor particle size and concentration.

The principle of operation is based on the detection of the scattering light induced by the particulate when passing through a laser beam.

The detectors system detects the light pulses and intensities which correspond to the number and size respectively of the different particle which are classified in the classic TSP, $\mathrm{PM}_{10}, \mathrm{PM}_{7}$, $\mathrm{PM}_{2,5}$, e $\mathrm{PM}_{1}$ classes. To the detected signal, corresponding to said classes, an empirical algorithm is applied to calculate the corresponding weights and the data is presented on the display in $\mathrm{mg} / \mathrm{m} 3$.
The analyser is designed to supply the data relative to the quality of the air in just 2 minutes. After calibration using a reference gravimetric system (FRM), the instrument can be used to supply low cost, real time and reliable measurements of PM concentrations specially when it is necessary to detect and evaluate the presence of peaks.

The AEROCET 531 is constituted by a sensor, a laser diode, a rechargeable NiCd battery pack, a pump, an isokinetic probe, a microprocessor, a LCD display, the interface for PC's, a battery charger and accessories included in a carrying case.

OPERATION: pushing <START STOP> the pump start and the sample is passed through the sensor chamber where the particle number and size are measured for 2 minutes, then the algorithm applies to calculate the 2 minutes average mass concentration, memorize it and presents it on the display in the TSP, $\mathrm{PM}_{10}, \mathrm{PM}_{7}, \mathrm{PM}_{2,5}$, e $\mathrm{PM}_{1}$ classes.

Programming of the AEROCET: 531 it is possible, using one lap top PC with the dedicated soft- 
ware, to download the memorised data and transfer it to Excel for successive elaborations.

The AEROCET 531 can be equipped with a temperature and relative humidity sensor.

As any other optical system, the AEROCET 531 is RH sensitive but there is no theoretical compensation for error correction. It is therefore recommended not to use the instrument when the RH exceed $60-65 \%$. However the following empirical table can be used not to eliminate the error but to minimize it.

$\%$

$\begin{array}{rc}\text { Relative Humidity } & \text { factor } \\ 40 & 1 \\ 45 & 1 \\ 50 & 1 \\ 55 & 0.96 \\ 60 & 0.91 \\ 65 & 0.85 \\ 70 & 0.77 \\ 75 & 0.67 \\ 80 & 0.56 \\ 85 & 0.45 \\ 90 & 0.33 \\ 95 & \mathrm{Na}\end{array}$

\subsection{Calibration}

The sensor is factory calibrated using PLS (polystirene latex) NIST traceable calibration particles.

The use of PLS is actually the most accurate system for the calibration of particle counters. The particle counting of the different sizes particles made by the AEROCET 531 is converted into mass using the algorithm having a default factor of 1.000 based on the ARD (Arizona Road Dust) since this ARD is assumed to have a particle size distribution and weight the most similar to most common aerosols.

However if the aerosol to be measured has a different size or mass distribution than the ARD, or the sample conditions such as temperature or humidity are different, there will be an error in the mass measurement. This error can be compensated: the algorithm includes 4 coefficients relatives to the particles sizes (p1, p2, p3 e p4 corresponding to the classes $\mathrm{PM}_{10}, \mathrm{PM}_{7}, \mathrm{PM}_{2,5}$ e $\mathrm{PM}_{1}$ respectively) and one more $\mathrm{k} 1$ for all sizes. (TSP)

The default values of these coefficients (p1,p2,p3,p4 e k1) are 1.000, corresponding to the ARD, and can be adjusted according to the results of the comparison of the instrument indication with the values of the gravimetric measurements.

\section{DESCRIPTION OF THE METHOD USED FOR THE CALIBRATION FOR ETS (Environmental Tobacco Smoke)}

Since differences in the morphology, composition, temperature, humidity and optical characteristics of the aerosol to be measured can introduce significant errors in the measurements, the calibra- tions have been made in one environment where it was possible to simulate the ETS pollution using a smoking machine and ambient conditions (temperature, humidity and barometric pressure) of the environments (mainly restaurants and pizzeria's, workplaces, offices, hospitals etc) where the measurements will have to be done. This procedure is commonly used to calibrate real-time particle monitors (a reference paper on the issue is: Jenkins RA, Ilgner RH, and Tomkins BA. Development and Application of Protocols for the Determination of Response of Real-Time Particle Monitors to Common Indoor Aerosols. Air \& Waste Manage. Assoc. 2004; 54:229-241).

The particulate size selected for the measurement of the ETS was the $\mathrm{PM}_{2.5}$ for the following reasons:

a) $\mathrm{PM}_{2.5}$ size is more representative of the real aerosol profile of the ETS which is composed mainly of particles of sub micrometric diameter.

b) However the gravimetric measurements of sub micrometric particles is still difficult and less accurate than that of the $\mathrm{PM}_{2.5}$.

c) Although $\mathrm{PM}_{2.5}$ cannot be considered as a specific marker of the ETS, it is more accurate than $\mathrm{PM}_{10}$ since scarcely affected by the presence of particles re-suspended by air turbulence due to the ventilation and/or the presence of persons.

d) Measuring contemporaneously both $\mathrm{PM}_{10}$ and $\mathrm{PM}_{2.5}$ can permit to discriminate between resuspended particles and particles produced by a combustion process such as the smoking of tobacco.

\subsection{PM $_{2.5}$ calibration for comparison with gravi- metric system}

Comparison has been made according to the norms in use actually in Italy: App. 2 of D.P.C.M. $\mathbf{2 8 / 0 3 / 1 9 8 3 ~ ( a l s o ~ i n ~ a c c o r d a n c e ~ w i t h ~ t h e ~ U S ~ F R M ) ~}$ and successive gravimetric determination. A total of three tests have been made in three consecutive days with $\mathrm{RH}$ ranging from 45 to $50 \%, \mathrm{~T}=22-24$ ${ }^{\circ} \mathrm{C}$ and barometric pressure 1,014-1,018 mBar.

The instrument to be calibrated has been operating at the prescribed height from the floor of 1.5 meters and at a distance of about 1 meter from the inlet head of the reference method sampler. The sampler used is the Mod. PF 20002A of Zambelli with membrane holder OPEN $\Delta 47 / 50 \mathrm{~mm}$, operating at the flow of 25 liters/min; the volume in cubic meters of air sampled was about 10,50 for the $\mathrm{I}^{\circ}$ test, 13,50 for the $\mathrm{II}^{\circ}$ and 10,50 for the $\mathrm{III}^{\circ}$ for a total of 34.50 cubic meters.

The pre-weighted filter has bees dried and reweighted with a Sartorius Semimicro Model BP211D range (=/210 gr. Div. 0.01/0.1 with 5 digits scale according to the procedure described in the above said norms.

The results have been certified by Dr. Vilma Fornasari of Chimicambiente S.a.s. of Guastalla (RE). 


\section{RESULTS OF THE MEASUREMENTS TESTS CONDUCTED ON NOV. 19TH. THRU NOV. 20TH. 2003}

\section{Comparison of Aerocet $\mathbf{5 3 1}$ with gravimetric reference method for PM2.5 Adjusted $K=1,93$}

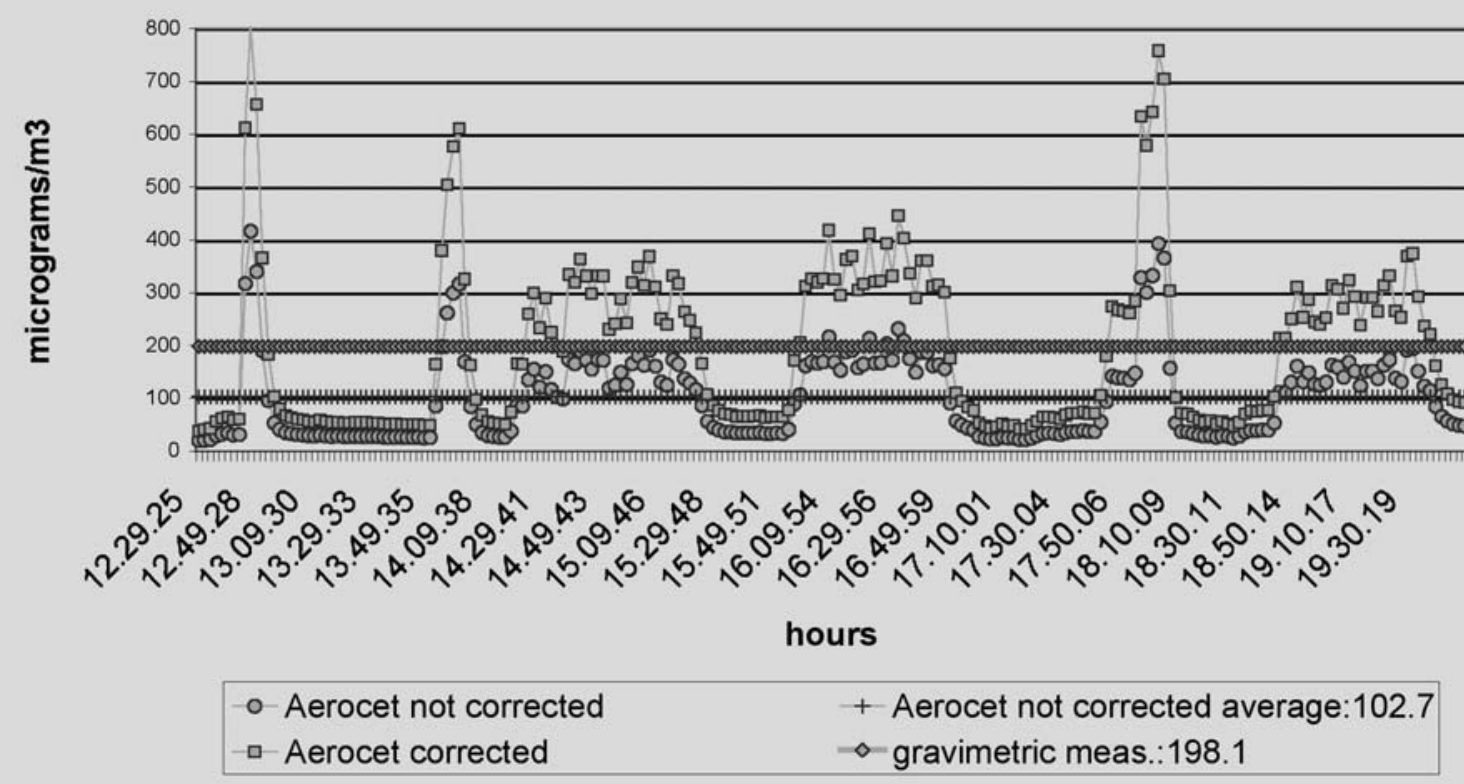

Fig. 1. - First test with total sampling of 7 hours and analysis of 10.50 cubic metres of air.

\section{Comparison of Aerocet $\mathbf{5 3 1}$ with gravimetric reference method for PM2.5 Adjusted $K=2,04$}



Fig. 2. - Second test with total sampling of 7 hours and analysis of 10.50 cubic metres of air. 


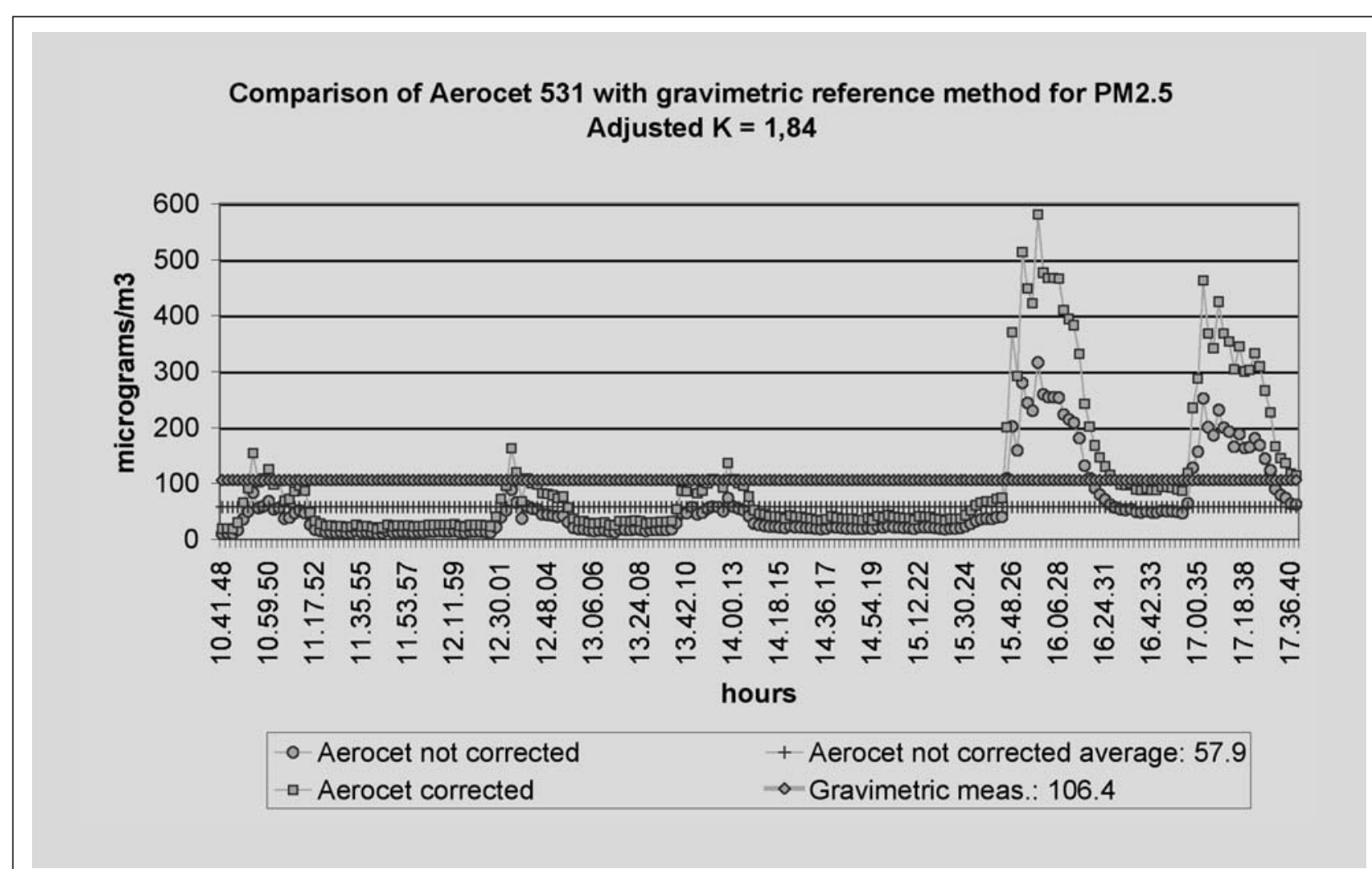

Fig. 3. - Third test with total sampling of 9 hours and analysis of 13.50 cubic metres of air.

Summary of the results

\begin{tabular}{c|c|c|c} 
Test \# & Gravimetric & Aerocet ave. & K corrected \\
\hline 1 & 198.10 & 102.70 & 1.84 \\
\hline 2 & 144.30 & 70.80 & 2.04 \\
\hline 3 & 106.4 & 57.90 & 1.84 \\
\hline Average & & & 1.90 \\
\hline SD & & & 0.11
\end{tabular}

\section{Correlation Plot of Aerocet 531 measurements and gravimetric reference method before $\mathrm{K}$ correction:}

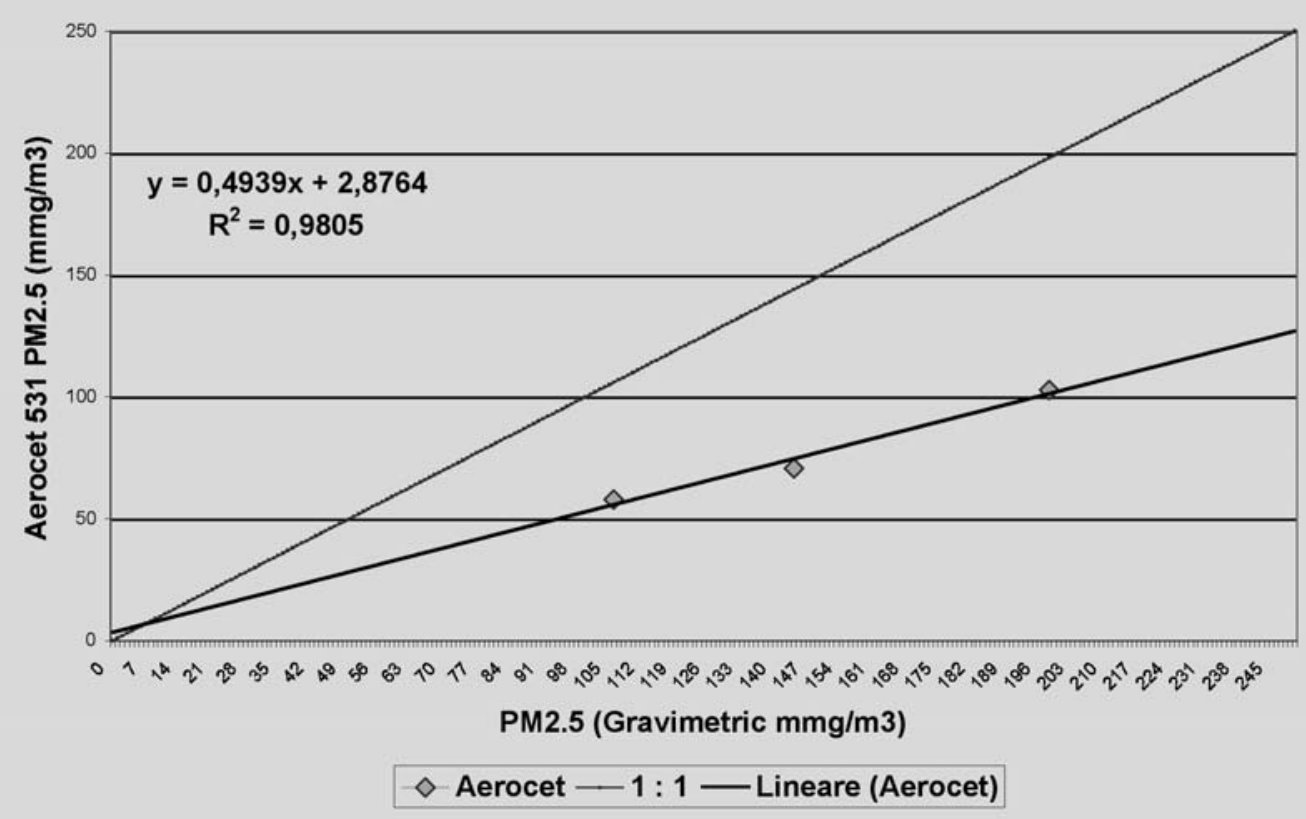




\section{Correlation Plot of Aerocet 531 measurements and gravimetric reference method after $\mathrm{K}$ correction:}
